\title{
The role of structure in the chemically induced deformations of FEBEX bentonite
}

\author{
Guido Musso $^{\mathrm{a}, *}$, Enrique Romero Morales ${ }^{\mathrm{b}, 1}$, Antonio Gens ${ }^{\mathrm{b}}$, Ernesto Castellanos ${ }^{\mathrm{b}}$ \\ ${ }^{a}$ Technical University of Turin, Turin, Italy \\ ${ }^{\mathrm{b}}$ Technical University of Catalonia, Barcelona, Spain
}

\begin{abstract}
The paper presents the experimental results of an investigation aimed at understanding the role played by the soil structure in the evolution of chemo-mechanical-coupled processes in bentonite. The objective was pursued by subjecting samples with different structures to similar salinisation-desalinisation cycles. Samples were prepared at approximately the same void ratio by means of either static compaction at hygroscopic humidity or starting from slurries consolidated under mechanical loads.

The investigation was carried out both from a macroscopic point of view (measuring the induced deformations) and from a microscopic point of view (ESEM analysis, mercury intrusion porosimetry). It is evidenced how the behaviour of the compacted samples differs from the one in the consolidated samples, especially as far as the evolution in time of the deformations is considered. An attempt to explain the differences by means of structural considerations is then provided.
\end{abstract}

(c) 2003 Elsevier B.V. All rights reserved.

Keywords: Chemical cycles; Deformations; Structural levels; NaCl; Swelling times

\section{Clay structure and chemically induced deformations}

\subsection{Structural levels in clays}

The importance of chemical swelling in smectitic clays has been observed by several authors, who have indicated its physicochemical causes (Van Olphen, 1977), proposed proper formulations of the stress variables (Fam and Santamarina, 1996) and shown the relevance of the phenomenon by means of laboratory experiments (Di Maio, 1996). If chemical

* Corresponding author. Fax: +39-11-564-4899.

E-mail addresses: guido.musso@polito.it (G. Musso), enrique.romero-morales@upc.es (E. Romero Morales).

${ }^{1}$ Fax: +34-93-4017251. swelling/shrinkage should occur in clayey soils used for waste disposal, it could imply the appearance of significant irreversible deformations, changes in hydraulic permeability and, in some cases, the appearance of cracks.

Notwithstanding that, most of the theoretical and experimental analyses available in literature focus only on the behaviour of samples reconstituted from slurries and not on the one of compacted clays. Compacted samples exhibit a complex structure incorporating several levels (with phenomena occurring at the microscale, at the mesoscale and at the macroscale), whose influence on physicochemical induced effects is far from clear.

According to Yong (1999), the microscale is adequate for investigating phenomena occurring at the level of the mineralogic layers. Aspects falling 
within the range of the microscale are such as the atomic interaction between the mineralogic layers and the ions dissolved in the wetting solution, or the one between mineralogic layers joining into a clay platelet.

The mesoscale regards the interaction of various clay platelets, connected into clusters and then into peds. The macroscale, at which all the macroscopic variables (such as effective stresses, volumetric and shear deformations) are currently measured, works with groups of peds, that can be adopted as fundamental brick of the representative elementary volume (REV) on which the macroscopic theories are based.

The space between mineralogic sheets can be identified as uls (unit layer separations), while the voids embedded in the peds constitute the micropores and those interposed between different peds, the macropores.

1.2. Chemically induced deformations

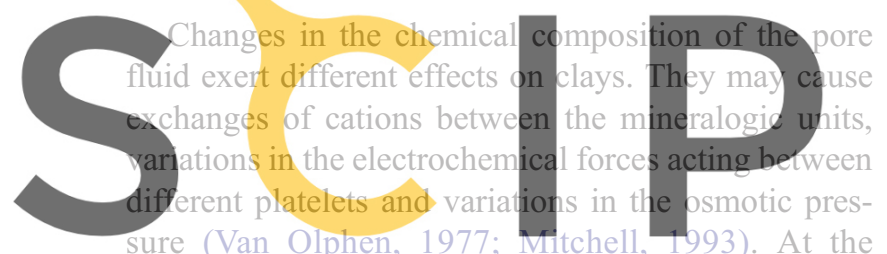

microscopic scale, the distance between different unit

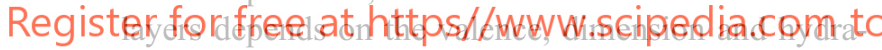
tion state of the interposed cations (for the importance of the latter in defining the sample permeability and its dependence on the cationic concentration see, e.g. Krishna Mohan et al., 1999). At the mesoscopic scale, ionic strength of the solution controls the repulsion forces between different particles as well as the osmotic pressure in the micropores. At the macroscopic scale, the distance between peds is such that the repulsion effect is lost while the effect due to changes in the bulk osmotic pressure remains.

According to the geotechnical literature, an increase in concentration in the pore solution leads to osmotic and osmotically induced consolidations (Barbour and Fredlud, 1989). Osmotic consolidation is induced by the reduction of the electrochemical repulsion forces. Deformations take place in the micropores and are reflected at the macrostructural level by rearrangement of the groups of peds.

Osmotically induced deformations occur when appropriate boundary conditions exist and significant differences in the osmotic pressure are acting in the soil mass. Indeed osmotically induced consolidation derives from the flow of bulk pore water as a response to chemical potential gradients. Tests described by Barbour and Fredlund, as well as the ones conducted by others researchers (see, e.g. Di Maio, 1996), show that usually osmotic consolidation has a larger effect than the osmotically induced one. Di Maio (1996) also showed a strong dependence of the osmotic deformations on the applied effective stresses and void ratio. In those tests, induced deformations and changes in the mechanical properties of the specimens proved to be irreversible only when the penetrating cation was potassium.

Several attempts have been performed to furnish a correct set of stress variables for the problem under examination. Bolt (1956) proposed a modified Terzaghi's effective stress that included a term due to electrostatic repulsion-attraction. Another way to deal with the problem is to consider the chemical effects by

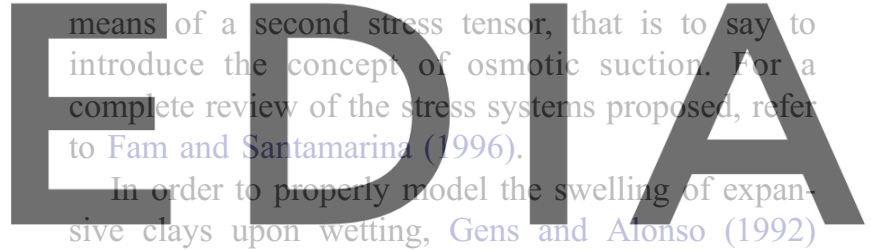

proposed a model formulated on the concept of downtead the versi pa writhautl the watermark

to incorporate chemical effects (Guimaraes, 2002). The basic idea is that chemical changes induce volumetric deformations at the mesoscale that are reflected at the macroscale through proper hysteretic interaction functions. The study of the relationship between the diffusion process, the deformations induced at the mesoscale and finally those measured at the macroscale were the aims of the investigation performed. Focus was pointed on compacted bentonite, a main component of engineering barriers used in the disposal of wastes.

\section{Samples characteristics. Porosimetry and ESEM observations}

\subsection{Soil properties}

The material studied was FEBEX bentonite, constituted mainly of montmorillonite (smectite percent- 
age higher than 90\%) and of variable quantities of quartz, plagioclase, K-feldspar, calcite opal CT. The material has a liquid limit of $102 \%$, a plastic limit of $53 \%$, specific gravity of 2.70 and a percentage of material smaller than $2 \mu \mathrm{m}$ of $67 \%$ (ENRESA, 1998). Four different samples (see Table 1 for main void ratios and mechanically imposed conditions) with an initial height of $10.5 \mathrm{~mm}$ were tested.

\subsection{Preparation of samples}

Mechanically consolidated samples, MC1 and MC2, were obtained starting from slurries of FEBEX powder and distilled water at initial water content $w_{\mathrm{i}} \approx 150 \%$. Slurries were placed in traditional oedometers where increasing mechanical stresses were applied so to induce mechanical consolidation until a vertical net stress of $1500 \mathrm{kPa}$. The vertical net stress was then reduced to $200 \mathrm{kPa}$ (sample MC1) and 500 $\mathrm{kPa}(\mathrm{MC2})$ so to reach the desired void ratio and the

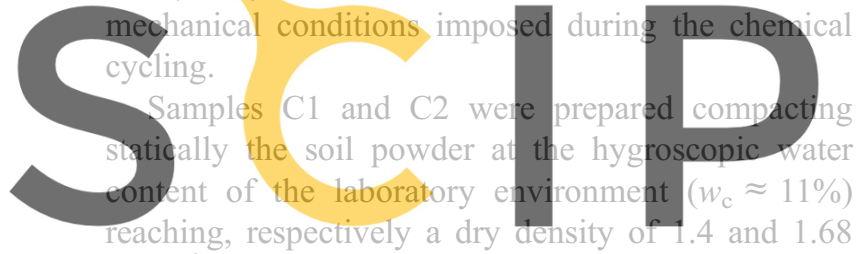

$\mathrm{Mg} / \mathrm{m}^{3}$. Samples as compacted were placed in the

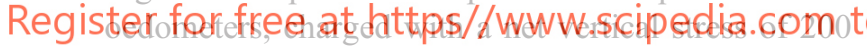

$\mathrm{kPa}$ and saturated by inflow of distilled water. Chemical cycling was then applied.

Stress paths of the two preparation procedures are given in Fig. 1, while Table 1 provides the initial void ratios and the effective stress conditions applied during the tests.

Tests $\mathrm{C} 1, \mathrm{MC} 1$ and $\mathrm{MC} 2$ were performed in traditional oedometers with the chemical boundary condition imposed in an 'open air' fashion replacing the

Table 1

Testing conditions of compacted and consolidated samples

\begin{tabular}{llll}
\hline Sample & $\begin{array}{l}\text { Initial } \\
\text { void ratio }\end{array}$ & $\begin{array}{l}\text { Void ratio } \\
\text { at saturation }\end{array}$ & $\begin{array}{l}\text { Applied } \\
\text { vertical net } \\
\text { stress }(\mathrm{kPa})\end{array}$ \\
\hline $\mathrm{C} 1$ & 0.87 & 1.23 & 200 \\
$\mathrm{C} 2$ & 0.60 & 0.84 & 200 \\
$\mathrm{MC} 1$ & 1.35 & 1.35 & 200 \\
$\mathrm{MC} 2$ & 1.25 & 1.25 & 500 \\
\hline
\end{tabular}

Matric suction

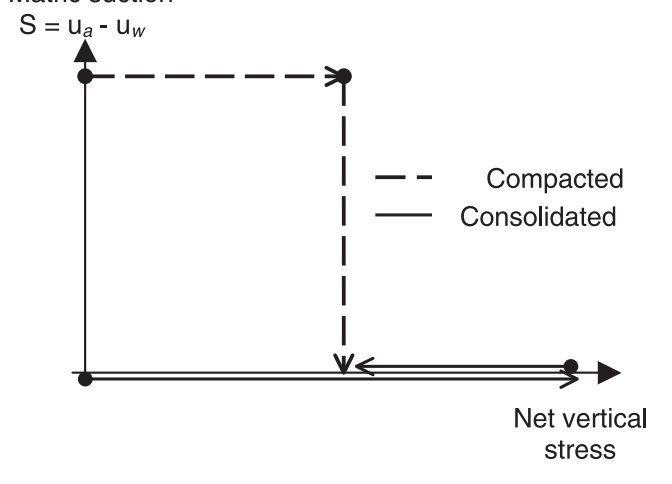

Fig. 1. Stress paths during the preparation of the samples.

fluid wetting the bottom porous stone (Fig. 2). Test C2 was conducted in a suction-controlled oedometer with the chemical boundary condition imposed through a liquid reservoir placed beyond the bottom porous In the salinisation path, a $5.5 \mathrm{M}$ solution of $\mathrm{NaCl}$
was used. $\mathrm{Na}^{+}$and $\mathrm{Cl}^{-}$idns were free to diffuse from
the porous stone inwards the sample and joduce
chemical consolidation. When conplete consolidation
was achieved, the distilled water boundary was applied, letting $\mathrm{Na}^{+}$and $\mathrm{Cl}^{-}$ions diffuse outside of download the version without the watermark

\subsection{Bulk water chemical composition}

A sample of slurry material was subjected to squeezing and the outcome liquid was chemically analysed in order to characterise the initial composition of the bulk water (see data in Table 2). Sodium resulted as being clearly the most abundant species in

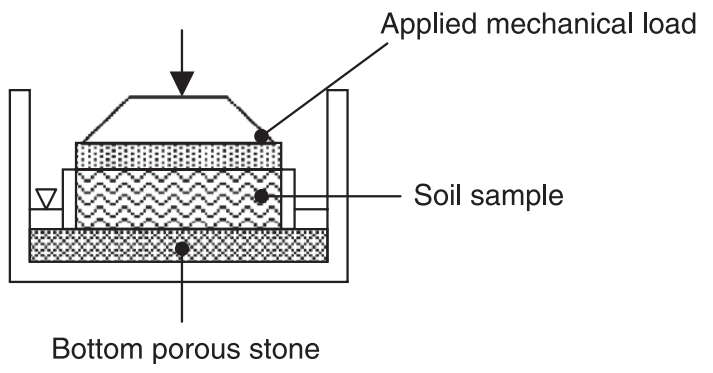

Fig. 2. Scheme of the traditional oedometer. 


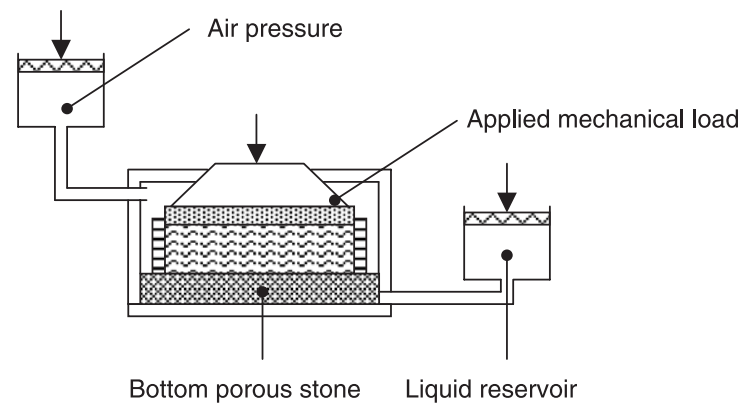

Fig. 3. Scheme of the controlled suction oedometer.

solution. Because of this, $\mathrm{NaCl}$ cycles are not expected to cause exchange of interposed cations. Deformations should therefore be the sum of the osmotic and of the osmotically induced ones. As no distinction between the two components was operated during the tests, in the following reference is generally made to 'chemical consolidation' and to 'chemical

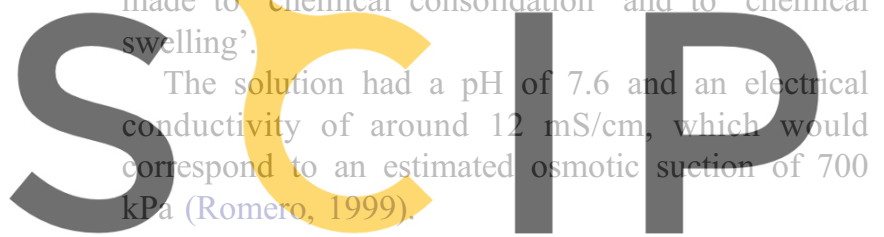

Register ${ }^{2}$ Initial pore size distribution and samples

Miercury intrusion porosimetry anaiyses were performed, following a freeze-drying process (see, e.g. Delage et al., 1982), to determine the pore size distribution of the samples prepared in different ways. Fig. 4 gives the results obtained for sample MC1 before the chemical cycles and for sample $\mathrm{C} 1$ in the as-compacted state. All the samples show two different peaks in the pore size distribution. The peak in the mesoscale is common for both samples and occurs at

Table 2

Relevant cationic species in the initial bulk water

\begin{tabular}{ll}
\hline Cation & Concentration (M) \\
\hline $\mathrm{Na}^{+}$ & $5.0 \times 10^{-2}$ \\
$\mathrm{~K}^{+}$ & $5.1 \times 10^{-4}$ \\
$\mathrm{Mg}^{2+}$ & $2.1 \times 10^{-3}$ \\
$\mathrm{Ca}^{2+}$ & $1.8 \times 10^{-3}$ \\
\hline
\end{tabular}

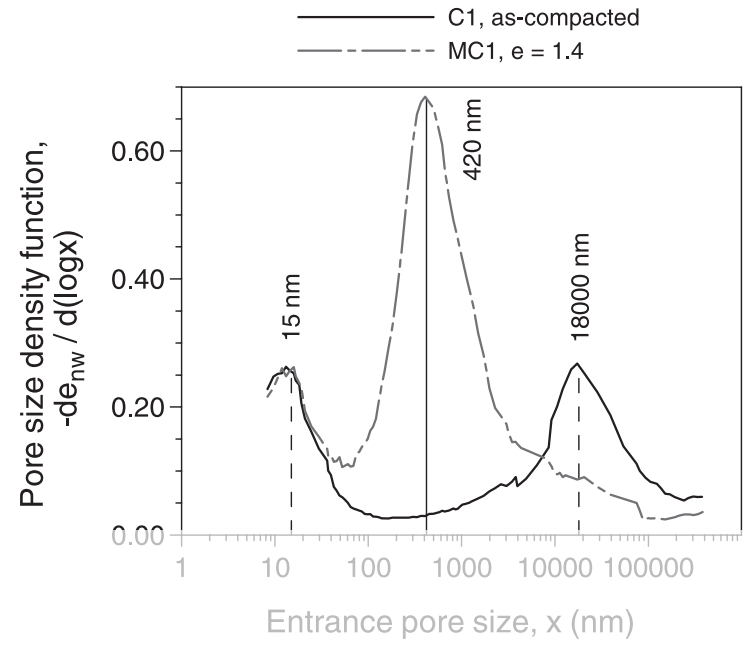

Fig. 4. Initial pore size distributions ( $\mathrm{Cl}$ compacted sample in unsaturated state, $\mathrm{MC} 1$ saturated sample before chemical cycling).

an entrance pore size of about $15 \mathrm{~nm}$. The peak in the

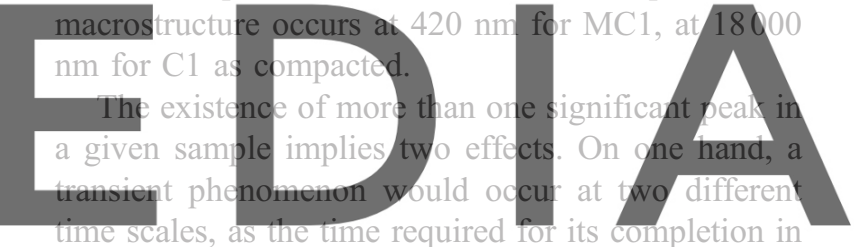

the micropores would be significantly bigger than the downl oadtsthe version withodd to theswatermark

Navarro and Alonso, 2001, for implications on the time evolution of mechanical consolidation). Moreover, as described earlier, at different distances between soil particles, different phenomena would occur. With reference to chemical cycles, pores with the smaller size are last to reach the final equilibrium concentration both in the salinisation as in the desalinisation paths. Also, macropores should be the place of occurrence of osmotically induced consolidation and micropores of osmotic consolidation.

Environmental Scanning Electron Microscopy (ESEM) analyses were pursued to highlight the structural differences between the different types of samples. Fig. 5 shows photomicrographs of sample MC1 before the chemical cycle and of sample $\mathrm{C} 1$ in the ascompacted state, both taken at the same magnification. Sample MC1 possesses a more uniform and homogeneous structure (matrix structure), in which peds are not clearly distinguished. The compacted sample, displaying an aggregated structure, shows 

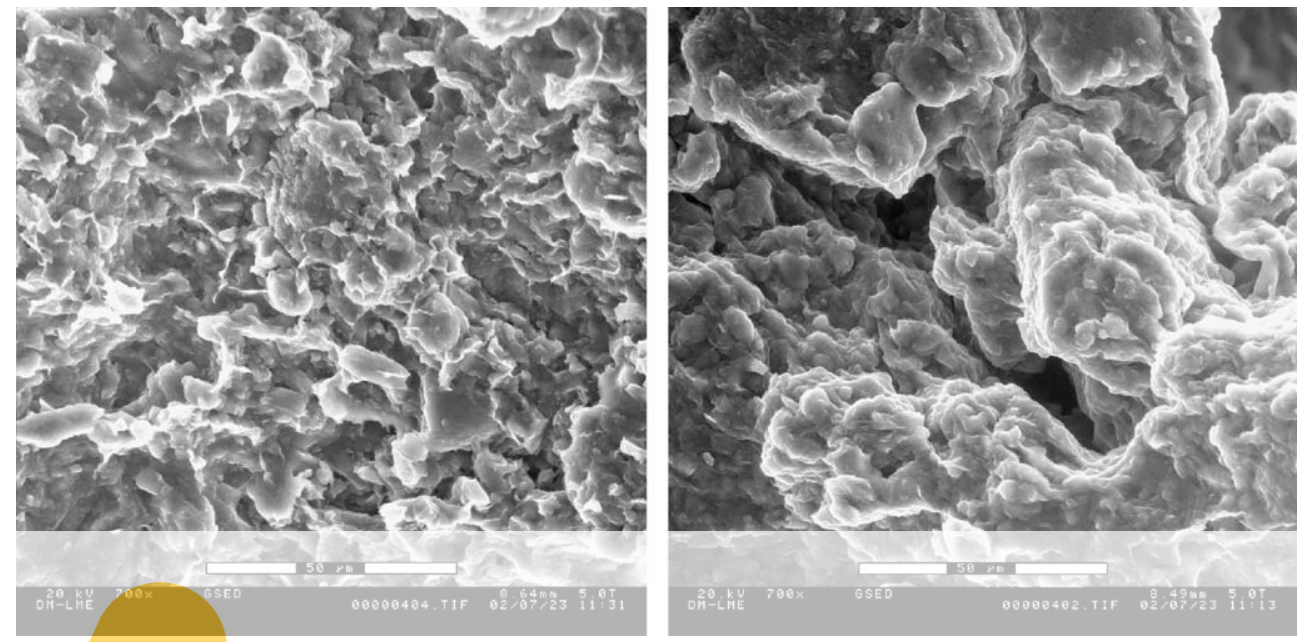

Fig. 5. ESEM picture of MC1 (left) and of C1 (right). Bar length $50 \mu \mathrm{m}$.

denser peds separated by pores of greater dimensions
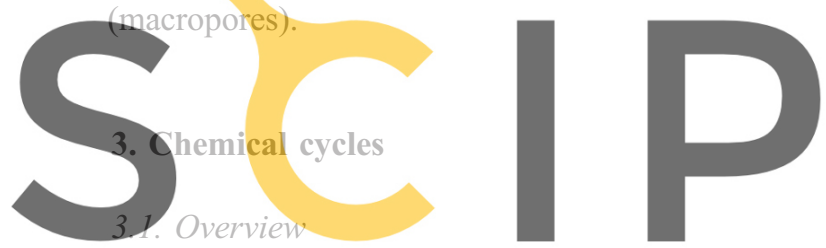

of the applied vertical stress. Chemical consolidation

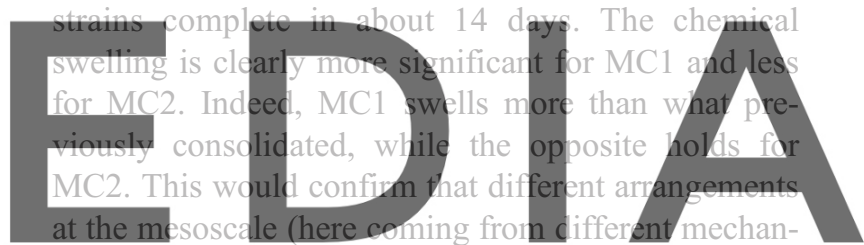

ical loads) lead to different macroscopic responses. In

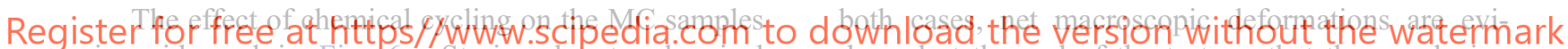
is evidenced in Fig. 6a. Strains due to chemical consolidation are close to 5\%, in line with typical results for bentonites. In the investigated range, chemical consolidation strains do not seem to be a function denced at the end of the test, so that the conclusion that a $\mathrm{NaCl}$ cycling induces not completely reversible strains could be derived. That nevertheless the fact that, given the initial composition of the bulk water

a

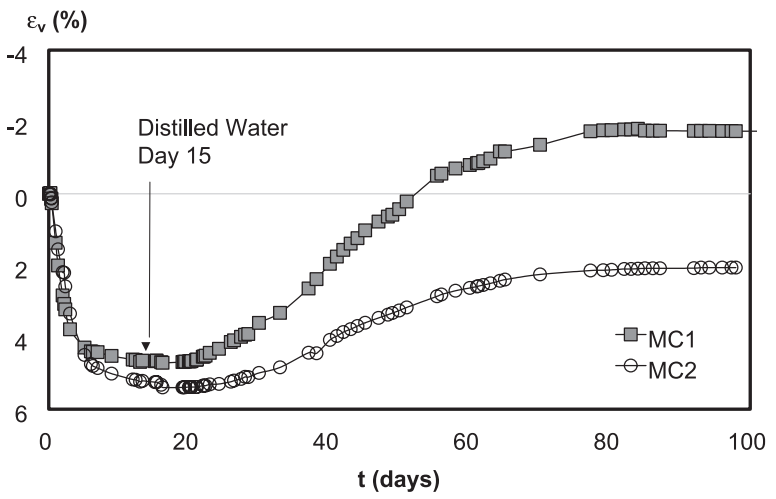

$\mathrm{b}$

$\varepsilon_{\mathrm{v}}(\%)$

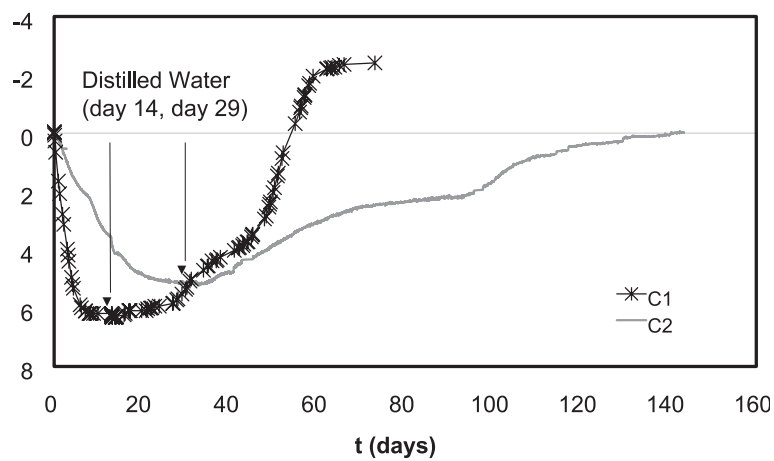

Fig. 6. Deformations during the chemical cycle in the consolidated (a) and in the compacted samples (b). 
and the solution used in the cycling, cation exchange deformations should almost not have taken place (Guimaraes, 2002).

In both compacted samples $\mathrm{C} 1$ and $\mathrm{C} 2$ salt diffusion inside the specimen induces consolidation strains quite comparable in magnitude with those of the consolidated samples (Fig. 6b). Anyway, once again, the swelling response is quite different in the two cases, as in $\mathrm{C} 1$ swelling strains are larger than consolidation strains whereas $\mathrm{C} 2$ shows a nearly perfectly reversible behaviour with respect to strain values.

\subsection{Chemical consolidation}

The time required for chemical consolidation appears to be approximately the same for all the samples with the only exception of C2 (Fig. 7a). Longer times of $\mathrm{C} 2$ are likely due mainly to the very low porosity of the porous stone adopted. This characteristic, jointly with the boundary conditions imposed in the suction controlled oedometer, cqused a big impedance to the system circulation of ions from the

\section{What diffusion times throug}

order of magnitude
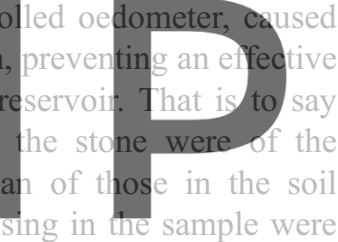

not replaced quickly enough by new ones from the

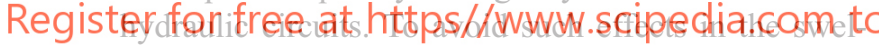

ling phase, the stone was replaced with a more porous one and periodically flushed.

By assuming that the constitutive relationship between concentrations and strains is linear (see
Barbour and Fredlud, 1989), it is found that the back calculated effective diffusion coefficient for the consolidated tests and for $\mathrm{C} 1$ ranges between $2 \times 10^{-6}$ $\mathrm{cm}^{2} / \mathrm{s}(\mathrm{MC} 2)$ and $3.6 \times 10^{-6} \mathrm{~cm}^{2} / \mathrm{s}(\mathrm{MC} 1)$. Those values are consistent with those obtained for a comparable material by the cited authors. Anyway, the reasonable objection that a linear relationship between strains and concentration is not accurate enough could be arisen (see, e.g. Alonso et al., 1994 for other relationships). In particular, if referral to the double layer theory is made, volumetric strains are more sensitive to concentration changes at low concentration values and less sensitive at large values.

Consolidation curves have been drawn in their non-dimensional form with respect to time and magnitude of the final strain in Fig. $7 \mathrm{~b} . T_{100}$ (time for completing the process) is about 14 days in all samples. The evolution in time of the strain ratio is common for all samples and quite continuous, with a

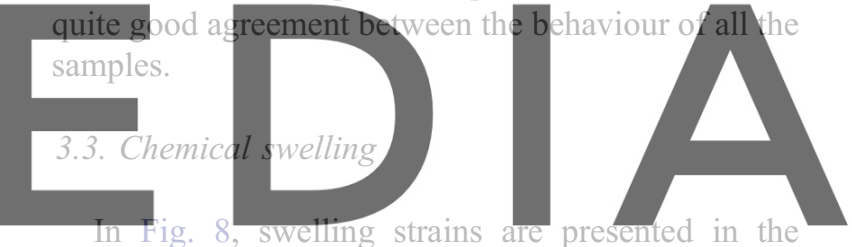

natural (a) and non-dimensional (b) form. It is interdowniloadnthehwersionnwithout thesy watermark with respect to the imposition of the distilled water boundary condition. Therefore, it is not possible to derive effective diffusion coefficients from these curves adopting the same procedure as in the consol-
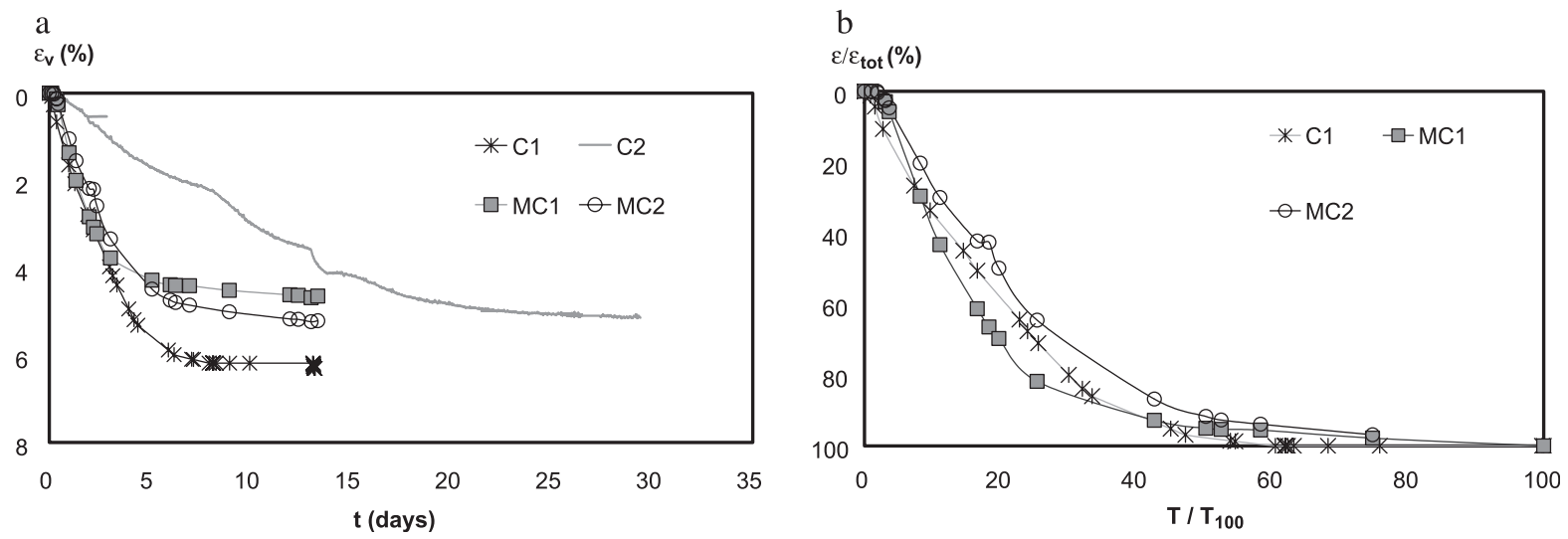

Fig. 7. Chemical consolidation paths in time (a) and non-dimensional (b). 

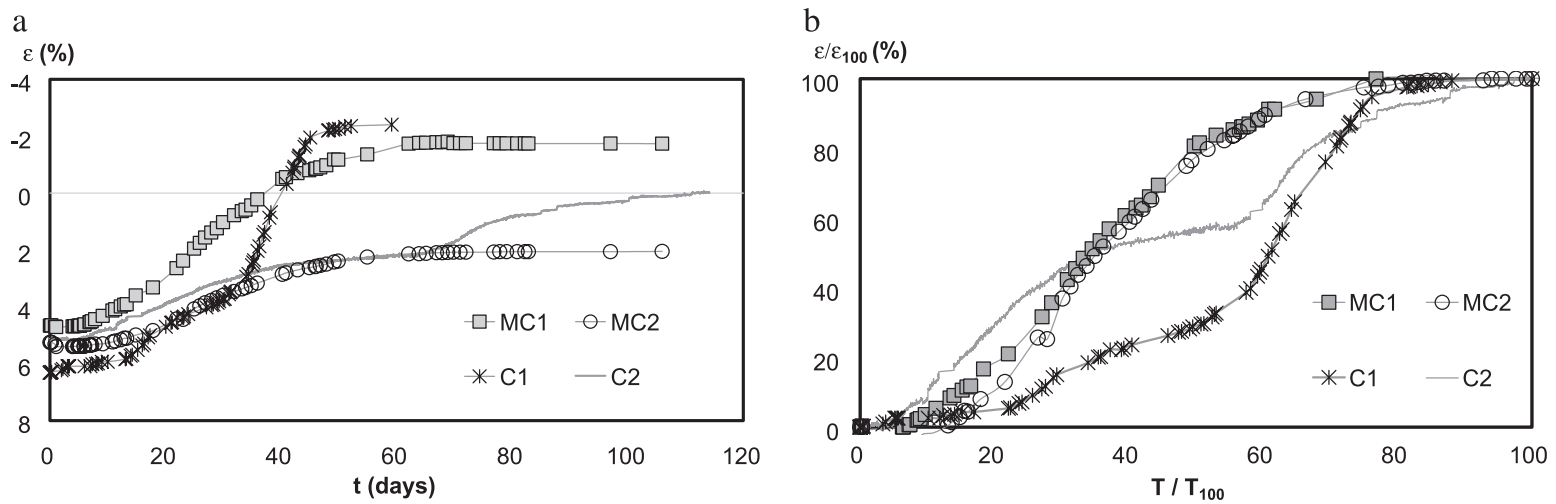

Fig. 8. Chemical swelling paths in time (a) and non-dimensional (b).

idation phase. Reasons for this phenomenon are not fully clear. Barbour and Yang (1993) state that a decrease of salinity in the pore fluid leads to a decrease in the inner (ped to ped) friction inducing rectistribution of peds and genera sion. This would be consistent reductions observed during

$\mathrm{MC}, \mathrm{MC2}$ and $\mathrm{C} 2$. More

etarded also because of the mentioned no-linear relationship between concentration and deformations.

Times for complete chemical swelling are signifi-

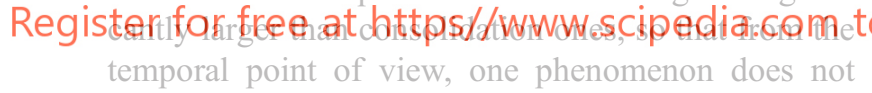
seem to be the reversal of the other.

The swelling response in time of the compacted samples is very different from the one of the con-

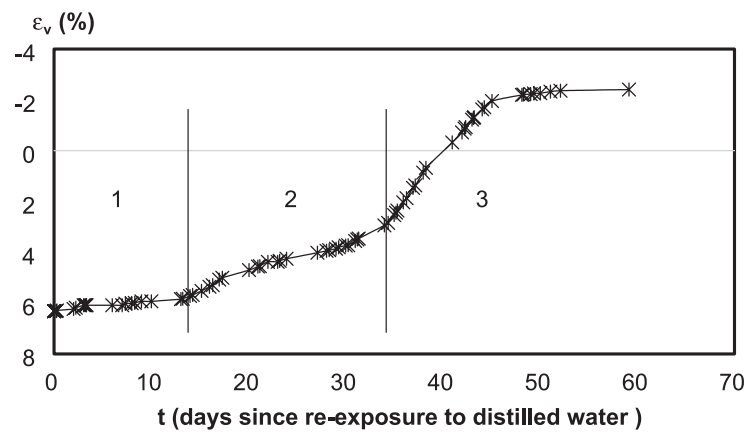

Fig. 9. Chemical swelling in sample $\mathrm{C} 1$ : subdivision in three time phases. solidated ones. Indeed, in the MC tests swelling occurs continuously without evidences of different times scales. In the compacted samples three time scales can be recognised. Referring to sample C1 (Fig.

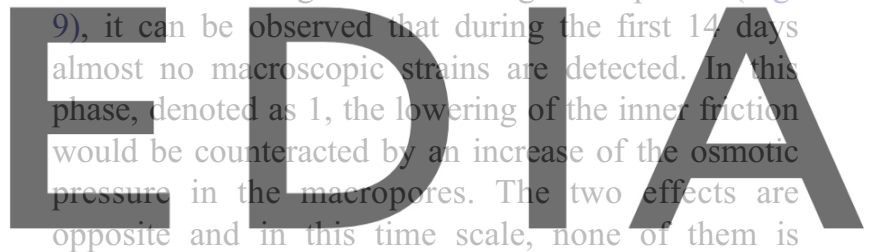

dominant. In the second time scale (between days download, thenvensiodidwithou tothecwatermark micropores and swelling is increasingly important. A quasi equilibrium condition is then reached. Phase 3 begins around day 34 , as the swelling rate increases noticeably again, and stops around day 45 when strain velocity drops close to zero. At the end of this latter phase, the equilibrium in the chemical potential between the fluid of the micropores and the one in the macropores should be finally reached. The same schematisation in three phases holds for sample C2, even though the whole process is dilated in time, probably because of its denser state.

\section{Pore size distribution during and after chemical cycles}

Mercury intrusion porosimetry tests were repeated to verify the effect of structure over the evidenced time scales in the swelling phase of the compacted samples (Fig. 10). A sample analogous to C1 was 

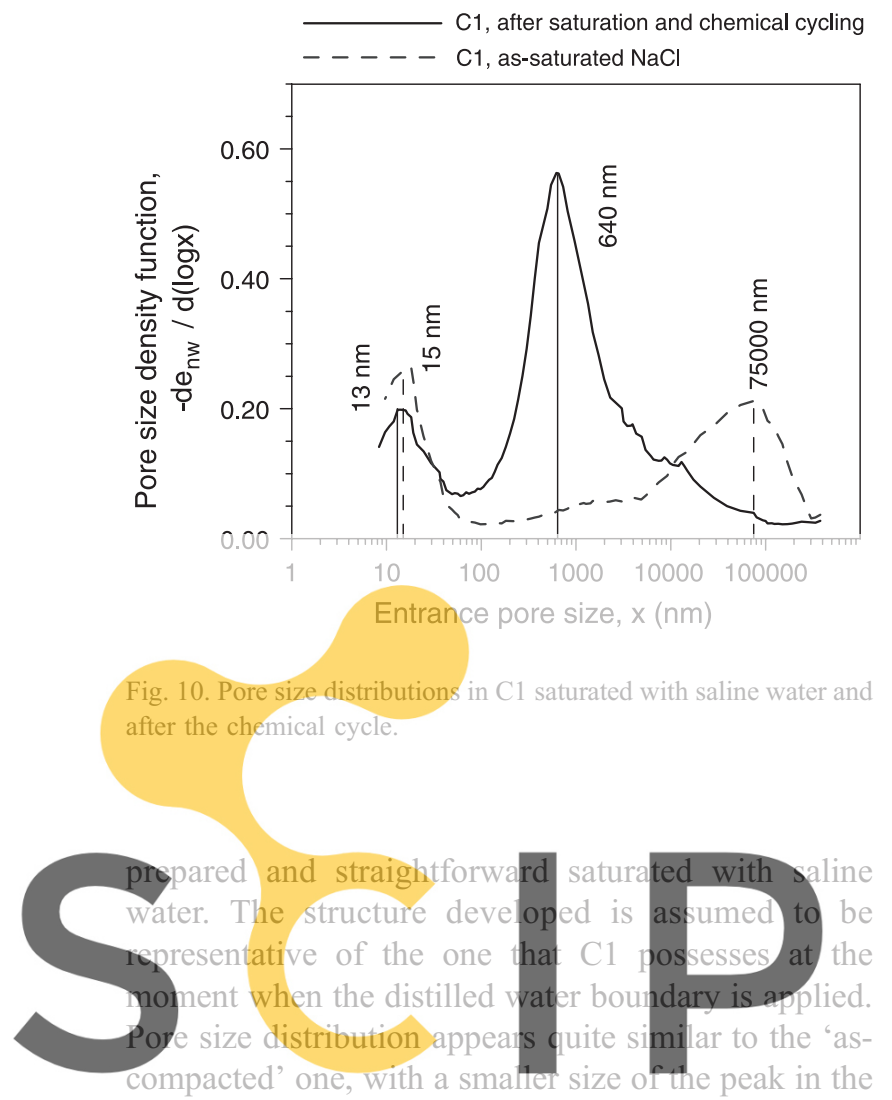

macropore range

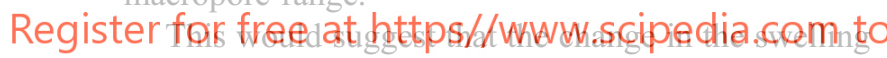
rate between the second and the third phases could be due to the very low percentages of pores whose diameter ranges between 100 and $10000 \mathrm{~nm}$, so that micropores are rather inaccessible. As a consequence, their ionic depletion would be rather difficult and delayed in time.

On the other hand, consolidated samples display a higher content of pores between 100 and 10000 $\mathrm{nm}$, so that micropores would be more accessible. Because of that, the diffusion process in the micropores would occur in a continuous manner and without the rate changes typical of the compacted samples.

The porosimetry test carried out on $\mathrm{Cl}$ after the end of the salinisation-desalinisation cycle (Fig. 10) shows pore sizes quite different from the initial ones, except for the micropore peak value. The consequences of the new arrangement on chemical strains still has to be evaluated as no results referring to a second chemical cycle are available yet.

\section{Conclusions}

Bentonite samples consolidated from slurry and bentonite samples compacted at two dry densities have been subjected to chemical changes consisting of a salinisation and desalinisation cycle. Significant chemically induced deformations over time have been observed. The pattern of strain development is quite different for the two types of samples. The difference has been explained in terms of different structural arrangements that have been independently estimated using porosimeter and ESEM observations. Very interestingly, the various structural levels present in the soil are reflected in the different time scales over which deformations develop.

\section{References}

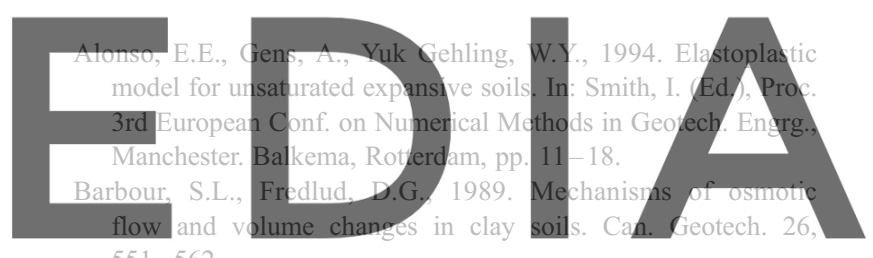

$551-562$

Barbour, S.L. Yang, N., 1993. A review of clay-brine interactions downhad the thersipnidsithout the ilwatermark soils from western Canada. Can. Geotech. 30, 920-934.

Bolt, G.H., 1956. Physico-chemical analysis of the compressibility of pure clays. Geotechnique 6 (2), 86-93.

Delage, P., Tessier, D., Marcel-Audiguier, M., 1982. Use of the Cryoscan apparatus for observation of freeze-fractured planes of a sensitive Quebec clay in scanning electron microscopy. Can. Geotech. 19, 111-114.

Di Maio, C., 1996. Exposure of bentonite to salt solution: osmotic and mechanical effects. Geotechnique 46 (4), 695-707.

ENRESA, 1998. FEBEX 'Full scale Engineered Barriers EXperiment in crystalline host rock-Pre operational stage summary report' Technical Publication 01/98. Madrid.

Fam, M., Santamarina, J.C., 1996. Coupled diffusion-fabric-flow phenomena: an effective stress analysis. Can. Geotech. 33, 515-522.

Gens, A., Alonso, E.E., 1992. A framework for the behavior of unsaturated expansive clays. Can. Geotech. 29, 1013-1032.

Guimaraes, L., 2000. Analisis multi-componente no isotermo en medio poroso deformable no saturado. Doctoral Thesis, Technical University of Catalonia.

Krishna Mohan, K., Reed, M.G., Scott Fogler, H., 1999. Formation damage in smectitic sandstones by high ionic strength brines. Colloids Surf., A Physicochem. Eng. Asp. $154,249-257$. 
Mitchell, J.K., 1993. Fundamentals of Soil Behavior, 2nd ed. Wiley, New York.

Navarro, V., Alonso, E.E., 2001. Secondary compression of clays as a local dehydration process. Geotechnique 51 (10), 859-869.

Romero, E., 1999. Characterisation and thermo-hydro-mechanical behaviour of Boom clay: an experimental study. Doctoral Thesis, Technical University of Catalonia.
Van Olphen, H., 1977. An Introduction to Clay Colloid Chemistry. Wiley Interscience, New York.

Yong, R.M., 1999. Overview of modeling of clay microstructure and interactions for prediction of waste isolation barrier performance. Eng. Geol. 54, 83-91.
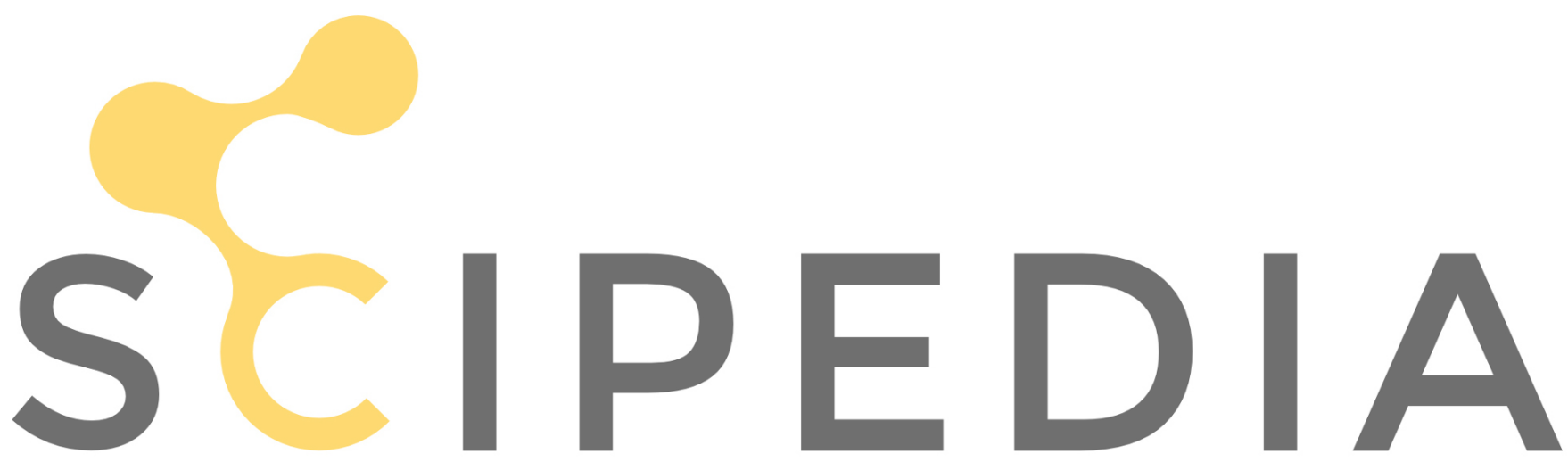

Register for free at https//www.scipedia.com to download the version without the watermark 